\title{
Operational costs of A 13,000 solar home systems rural electrification programme
}

\author{
L.M. Carrasco , L. Narvarte, E. Lorenzo
}

\begin{abstract}
A B S T R A C T
This paper presents an assessment and evaluation of the costs of operation and maintenance $(O \& M)$ in a real PV rural electrification (PVRE) programme, with the aim of characterizing its costs structure. Based on the extracted data of the 5-years operational costs of a private operator, the programme has been analyzed to take out the most relevant costs involved in the O\&M phase as well as the comparative appraisal between the 3 main activities: installation, O\&M and management. Through this study we try to answer to the new challenge of decentralized rural electrification based on larger programmes (with tens of thousands of SHSs) and longer maintenance and operation periods (at least 10 years).
\end{abstract}

\section{Contents}

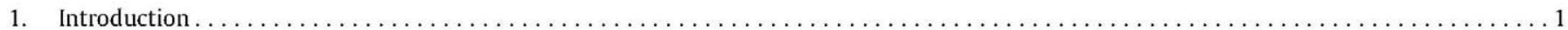

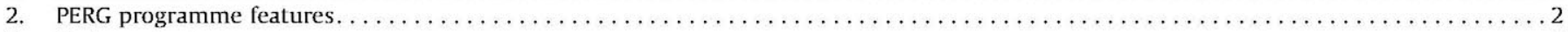

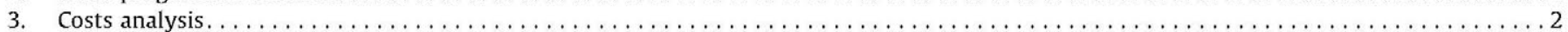

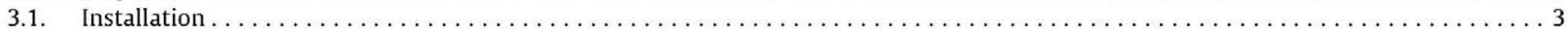

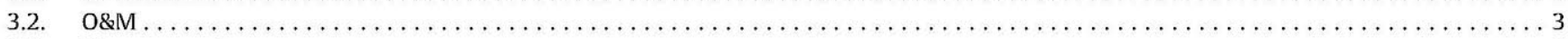

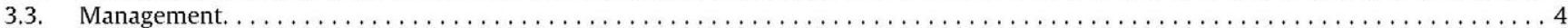

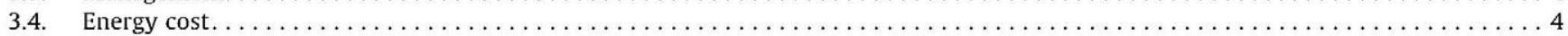

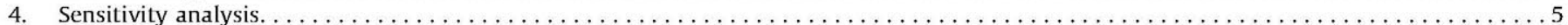

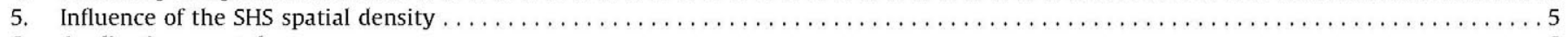

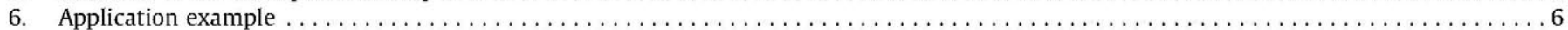

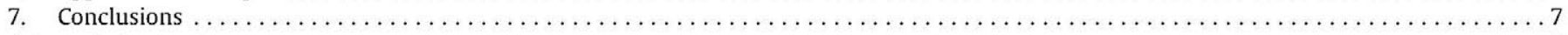

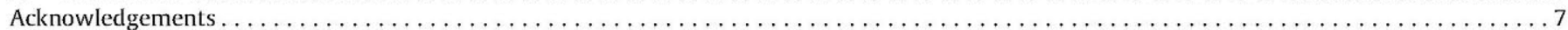

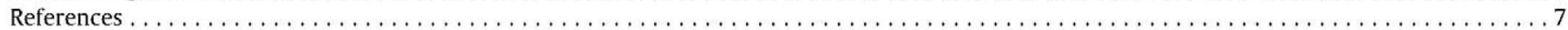

\section{Introduction}

Most PV rural electrification projects based on solar home systems (SHSs) and fee for service concept [1,2] have failed because real operation and maintenance $(0 \& M)$ costs are larger than initially expected [3-5]. Fees lower than real cost produces serious financial imbalances, making O\&M unfeasible and leading to the desertion of SHSs by the local operator.
In fact, despite many programmes and subsequent evaluations has been carried out since 1970s [6-14], real O\&M costs are scarcely reported at the available literature [15], making difficult the task of designing new SHSs programmes.

This paper reports on the fee for service programme (Programme d'Electrification Rural Global, PERG) awarded to the energy service company (ESCO) Isofoton in Morocco [16,17]. The programme has been developed in a region consisting of 12 provinces, covering around $200,000 \mathrm{~km}^{2}$, and having more than 13,000 installed SHSs at the end of 2010. A previous paper [18] gave statistically meaningful data on the reliability of SHS components, mainly in terms of failure rates and mean time to failure (MTTF). Now, we present the distribution of real costs 
(installation, O\&M and management) from the operational data of the ESCO Isofoton during 5 years, and we discuss the influence of some key aspects as battery and geographical dispersion.

\section{PERG programme features}

In the operative frame, the ESCO was responsible to sell the SHSs directly to the final users through a fee for service mechanism, as well as its furniture and installation within the 3 first years of the programme (from 2006 to 2008). The SHS consists of a $80 \mathrm{Wp}$ mono-crystalline silicon cells photovoltaic module (the manufacturer indicates a power peak tolerance of $\pm 5 \%$ and the program requires a minimum power of $75 \mathrm{~W}$ ), a $150 \mathrm{Ah} \mathrm{C}_{20}$ leadacid battery (modified SLI), a $15 \mathrm{~A}$ series charge controller with PWM regulation and without MPPT function, 4 compact fluorescent lamps $(\mathrm{CFL})(3 \times 7 \mathrm{~W}$ and $1 \times 11 \mathrm{~W})$, and a DC plug for small devices (less than $50 \mathrm{~W}$ ). Electrical efficiency of this lamp model, according to recognized laboratory tests, shows a value of $81 \%$ at $13 \mathrm{~V}$. Similarly, charge controllers have a charge and discharge efficiencies around $99 \%$.

The photovoltaic PERG programme has been designed by the Moroccan utility ONE. The sizing of SHSs and the components requirements have followed the recommendations of the Universal technical standard for solar home systems [19], in addition to the IEC-61215 for PV modules, the IEC- 60811 for wires, the EN61057:2000 and EN55015:200 for lamps and the EN55014-1 and EN55022 for charge controllers.

Table 1

Geomorphological distribution of the region.

\begin{tabular}{llll}
\hline Mountains $\left(\mathrm{km}^{2}\right)$ & Hills $\left(\mathrm{km}^{2}\right)$ & Desert $\left(\mathrm{km}^{2}\right)$ & Plain $\left(\mathrm{km}^{2}\right)$ \\
\hline $\mathbf{1 0 1 , 2 1 4}$ & $\mathbf{2 7 6 0}$ & $\mathbf{7 3 , 0 6 8}$ & $\mathbf{2 1 , 0 0 9}$ \\
$\mathbf{5 1 . 1} \%$ & $\mathbf{1 . 4 \%}$ & $\mathbf{3 6 . 9} \%$ & $\mathbf{1 0 . 6} \%$ \\
\hline
\end{tabular}

The installed SHSs are subject to a 10 years maintenance period. The ESCO must guarantee the systems during this period and must repair or replace damaged components. The ESCO is also responsible of collecting the monthly fees that the users must pay for the maintenance service. These fees are established by the electrical utility ONE (Office National de l'Electricité) in $4.92 \mathrm{\epsilon} /$ month/SHS (excluding VAT), that it is equivalent to $59.04 € /$ year/ SHS. This fee amount will remain unchanged over the 10 years of maintenance service.

The PERG region is geo-morphologically characterized to be located, partly, in a mountainous area (50\% of the region is covered by 3 mountain ranges: the Medium Atlas, the Grand Atlas and the Antiatlas), and partly by wide desert areas (Table 1). These features give to the region a difficult accessibility and a wide dispersion of villages and households.

In Fig. 1 appears the SHS density corresponding to the PERG provinces. The extremely low geographical density of SHSs is a remarkable feature of the region: $0.068 \mathrm{SHSs} / \mathrm{km}^{2}$, what means that there is 1 SHS per $14.7 \mathrm{~km}^{2}$. There are just two provinces, Al Kalaa des Sraghnas and Beni Mellal, whose density is largest than $0.4 \mathrm{SHSs} / \mathrm{km}^{2}$. In the vast majority of the region, the density is lower than $0.1 \mathrm{SHS} / \mathrm{km}^{2}$, coinciding with the most mountainous and desert areas.

\section{Costs analysis}

We will distinguish 3 main activities (see Fig. 2): installation, o\& $\underline{M}$ and general management. The installation refers all the works and activities required to install the SHSs, as well as the purchase of equipments and the marketing. The operation and maintenance of the systems requires the technical maintenance of the SHSs (including spare parts) and the collection of user's fees.

The general management (ESCO headquarter, management staff, etc) is linked to the others, so, it can be considered as an indirect cost of them. However, the management has been taken into account as an independent activity in this study.

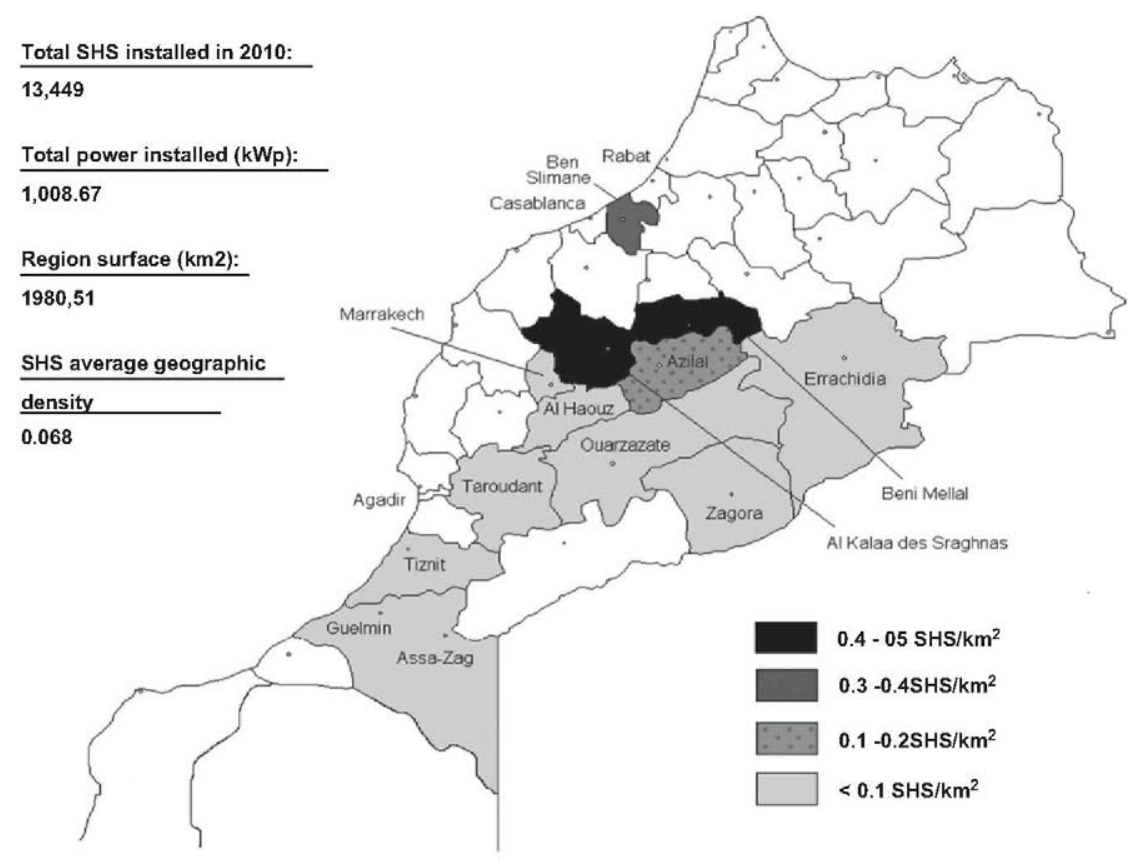

Fig. 1. Moroccan region belonging to the Isofoton PERG programme. The different areas. show the SHS density for each province (Province map before 2010 new region organization). 
The different costs as taxes, banking fees, assurances, staff training, office supplies, contingences fees, financial expenses, transports, customs, etc, are included in these 3 activities according to their involvement in each one.

The costs of the first 5 years of the PERG programme are shown in Fig. 3 and Table 2: from 2006 to 2008 the activity was mainly devoted to the installation of the SHSs, and 2009-2010 to the operation and maintenance service. Obviously, O\&M was also carried out from 2006 to 2008 for already SHSs installed.

The total expenses in these 5 years reached the amount of 12.5 MM $€$, distributed as shown in Fig. 3. Note that we have considered every expense involved in the development of the programme, taking into account all operative and financial costs before amortizations.

Given the failure rate of the SHS components in this programme [18], and considering that the total number of SHSs installed in $2008(13,449)$ remains practically fixed, it is reasonable to suppose that the O\&M costs in 2010 are representative of the following years. Therefore, we can calculate the whole cost of the programme after the 10 years period of O\&M just making the hypotheses that the yearly discount rate will be similar to the inflation rate in the coming years.

In this way, the PERG programme, whose completion year will be in 2018, will have a global cost of $21.2 \mathrm{MM} \epsilon$, which expressed in euro per unit power peak installed is $\mathbf{2 1} € / \mathbf{W p}$, and referred to the whole installed systems is $\mathbf{1 5 7 4} € /$ SHS.

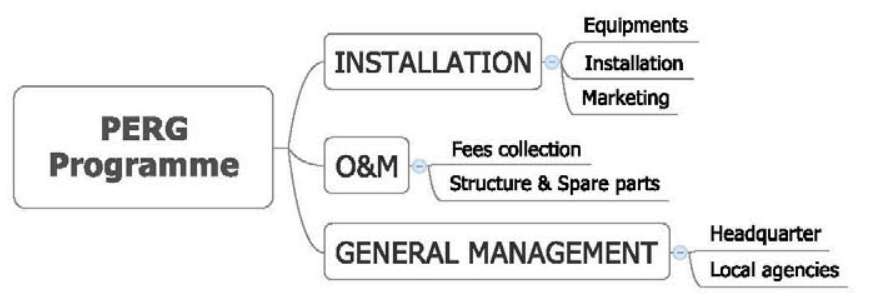

Fig. 2. PERG programme activities.

Table 2

Resume of the different activity costs within the 5 first years of the programme.

\begin{tabular}{|c|c|c|c|c|c|}
\hline Activity & 2006 & 2007 & 2008 & 2009 & 2010 \\
\hline Equipements & $478 €$ & $461 €$ & $454 €$ & - & - \\
\hline Installation & $87 €$ & $84 €$ & $81 €$ & - & - \\
\hline Marketing & $94 €$ & $80 \epsilon$ & $64 €$ & - & - \\
\hline Fees collection & $12 €$ & $10 €$ & $8 \epsilon$ & $26 €$ & $24 €$ \\
\hline Maintenance and spare parts & $15 €$ & $15 \epsilon$ & $16 e$ & $33 €$ & $40 €$ \\
\hline General management & $112 €$ & $54 €$ & $36 €$ & $23 \epsilon$ & $18 €$ \\
\hline Total & $798 €$ & $704 €$ & $659 €$ & $82 €$ & $82 €$ \\
\hline
\end{tabular}

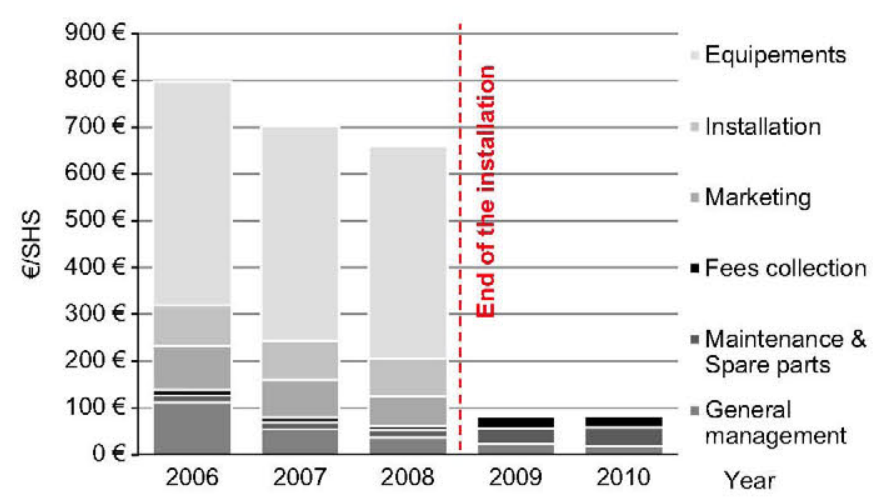

Fig. 3. Distribution of actual costs in the first 5 years of programme.
We can appreciate in Fig. 4 that the installation costs are similar to the O\&M costs for the whole programme period, and that the major costs are the initial equipment $(29.4 \%)$ in the installation phase, and the maintenance activity including spare parts (26.5\%).

\subsection{Installation}

We must consider that the equipment costs, in the installation phase, was influenced by two important facts: (1) the sell prices of the PV modules experienced an unexpected increasing regarding the previous years, reaching in a price of $3.5 € / \mathbf{W p}(262 € / S H S)$ in 2006-2008 period; (2) the lead market prices shot up reaching bounds greater than 4 times its cost in 2005, which affected directly the battery costs, whose final price depends in $50 \%$ of the lead cost, reaching $0.75 € / \mathrm{Ah}$ (or $1.51 € / \mathrm{Wp}$ ). So, the purchase cost of the PV kits was around $\mathbf{6 . 2} € / \mathbf{W p}$ (465 $€ / S H S$ ). Note that, at the photovoltaic market current prices of 2012 (0.8 €/Wp for PV modules), the cost of this PV kit would be around $3.7 € / \mathbf{W p}$ (277 $€ / S H S)$. However, this dramatic reduction in PV module cost means just $11.6 \%$ of decrease in the cost of the programme, showing that the cost of PV module is not the key point in decentralized rural electrification.

\section{2. $O E M$}

Maintenance includes both spare parts and the maintenance structure. Its cost represents $26.5 \%$ of the global programme cost,

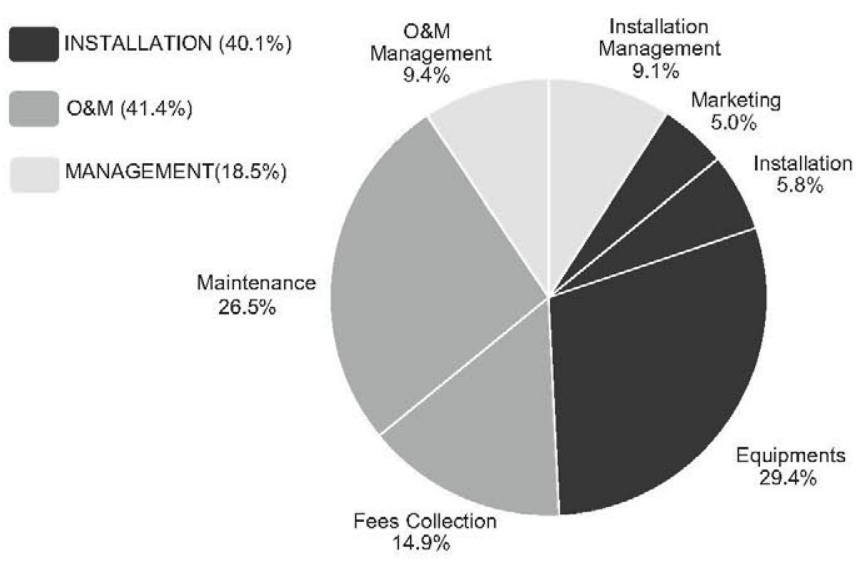

Fig. 4. Global cost distribution of the PERG programme for 13,449 SHSs and $1.008 \mathrm{MWp}$ installed (considering $75 \mathrm{Wc} / \mathrm{SHS}$ ). Percentage distribution of costs for each group of activities.

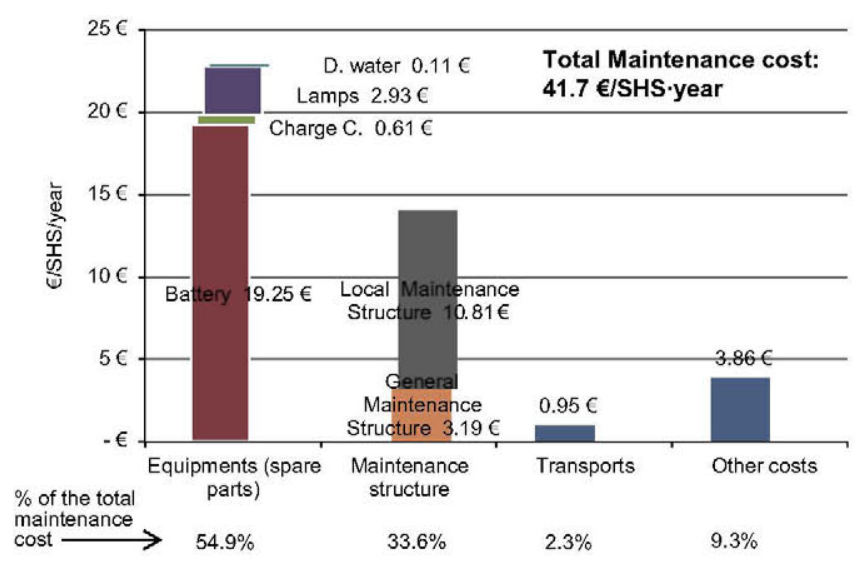

Fig. 5. Maintenance cost structure. 
as observed in Fig. 4, and it can be expressed as an annual $\mathbf{9 . 0 1} \%$ of the equipment investment ( $41.7 \mathrm{\epsilon} / \mathrm{SHS}$ - year). This figure is so far from other figures found in some publications [20-21], where maintenance cost is estimated at $1-3 \%$ per year of the equipment investment.

costs involved directly in the maintenance are shown in Fig. 5. We appreciate that the cost of the spare parts is the most important ( $22.9 \mathrm{E} / \mathrm{SHS}$. year), especially battery, which represents $19.25 \mathrm{€} / \mathrm{SHS}$ - year (according to $\mathrm{MTTF}=5.5$ years [18]), followed by lamps: $2.93 \mathrm{\epsilon} / \mathrm{SHS}$. year (MTTF $=16.5$ years).

The second largest cost of the maintenance is the maintenance structure ( $14 € / \mathrm{SHS}$ - year). This structure refers to the direct costs of this activity related to staff, offices, stores, vehicles, fuel, telephone, etc. These costs are divided between the local structures close to the SHSs, as local agencies, technical staff, etc; and the general structure located in the ESCO headquarter. Over 3/4 of costs falls on the local maintenance structure (10.81 $\mathrm{E} / \mathrm{SHS}$. year), versus the general maintenance structure (3.19 $\mathrm{E} / \mathrm{SHS} \cdot$ year). This data confirms again that the decentralized character is a very important factor in a PVRE programme: for example, the cost of fuel is as high as $5.5 \mathrm{E} / \mathrm{SHS}$. year, and the annual rate of distance per SHS traveled by the O\&M vehicles reaches $57 \mathrm{~km} / \mathrm{SHS}$ - year.

Distillated water cost $(0.11 \mathrm{e} / \mathrm{SHS}$. year $)$ is associated to the open lead battery used in this programme. However, the cost of the maintenance linked to the distilled water for the batteries means $30 \%$ of the total cost of the battery maintenance (the part of the overall maintenance cost intended for the battery, which includes the spare parts, a part of maintenance structure, transports and other costs), and represents $6 \%$ of the overall cost of the programme (9.5 $€ / \mathrm{SHS}$ - year). This activity requires to move to the SHSs at least once per year, and recommendable once each 6 months. This opens the door to evaluate the convenience of using "free maintenance" batteries, which do not require this practice.

Within the maintenance activity, the cost of transports refers to the transport of spare parts to supply the local stores, plus import of goods which are acquired outside of the country. Under "other costs" we refer the documentation (maintenance forms), financial expenses and other contingencies.

Other of the major costs of the programme is the fees collection activity ( $14.9 \%$ of the total cost - or $23.4 \mathrm{E} / \mathrm{SHS}$ - year - as shown in Fig. 4). The method to carry out this activity is based on the daily presence of the ESCO staff in the main rural communities from each region, coinciding with the days in which the local markets (souks) are organized, and demands a great effort in human capital and mobility, which justifies its high cost.

In addition there is another circumstance that turns the activity even more expensive: the non-payment management. When the user does not pay the monthly fee for more than 3 months, the ESCO agents must move to the user dwelling in order to collect the arrears, or even to rescind the subscription contract and remove the PV system. This activity is very delicate and it further increases the cost of the fees collection work. After the end of the installation phase, in 2009, the ESCO rescinded 151 customer contracts because of non-payment of monthly fees.

Considering all of the O\&M costs over the whole duration of the project (2006-2018), we can get the average yearly cost of the O\&M: 76.03 $€ /$ year. SHS, being the yearly user fees just $59.09 € /$ year.SHS. Making a cash-flow balance for a $\mathbf{5} \%$ constant annual discount rate, and given a ideal collection rate of $100 \%$, we will reach a total deficit of $\mathbf{3 . 4} \mathbf{M M} \in$ for the O\&M activity over the whole project duration.

This deficit, which is now a thorny reality for the ESCO's financial statements, reflects the lack of knowledge that exists about the O\&M costs when designing a PVRE programme. That is the case of many other programmes carried out before, such as
South Africa [3] (monthly fee: 6 US\$/SHS · month), Zambia [4] (12 US\$/SHS · month), Peru [22] (5-8 US\$/SHS - month), Tunisia [12] (5.20 US\$/SHS · month), Pacific Islands [13] (5 US\$/SHS · month), etc, where the ESCOs suffered important economic losses because low user fees were established. Therefore, we can conclude that the O\&M is, in general, an activity more expensive than expected; moreover, the fees paid by the users for the maintenance service are generally lower than necessary. These two facts lead to an unsustainable financial situation of the PVRE programmes.

In order to evaluate the accumulative costs of the main SHS components during the whole duration of the programme, we present Fig. 6, where it is represented the component cost due to the installation but also due to their replacement when fails (initial installation + spare parts).

From Fig. 6 it is deduced that the more important cost of the programme it is not the PV module, but are the battery and the general management (both 18.5\%). The PV module cost, of course, is significant, but it means just $15.5 \%$ on the global cost. Considering 2012 PV market prices, the PV module would mean only $4.36 \%$ of the programme cost.

\subsection{Management}

It must be underlined the relevance of the general management activity within the cost structure $(18.5 \%$ over the global cost, as shown in Figs. 4 and 6). The ESCO had designed the management structure for a 34,500 SHSs programme, as initially planned. The lack of potential customers and the electric grid expansion achieved by the ONE, limited dramatically the number of SHSs installed despite the commercial efforts carried out by the ESCO. This fact suggests that the size of the PVRE programmes must be big enough to support the high cost of decentralized management structures.

\subsection{Energy cost}

Finally, we can reach a figure of the electricity cost by calculating the electricity available for the users during the whole duration of the project. Taking into account that the daily average radiation on the tilted surface is $5.5 \mathrm{~kW} \mathrm{~h} / \mathrm{d} / \mathrm{m}^{2}$ and considering the performance looses, we obtain an available global production of $16.21 \mathrm{GW}$ h for the 13,449 SHSs over 10 years, leading to a cost of $1.30 \mathrm{E} / \mathrm{kW}$ h (no so far from the figures of other programmes, e.g., India: 0.65-1.35 US\$/kW h [23], Zambia: 1.6-2.1 US\$/kWh [24] or some African countries: $0.45-1.30$ US $\$ / \mathrm{kW}$ h [25] ). On the other hand, the tariffs of on-grid electricity in Morocco goes from $0.08 \mathrm{€} / \mathrm{kW}$ h to $0.13 € / \mathrm{kW} \mathrm{h}$ according to the quantity consumed,

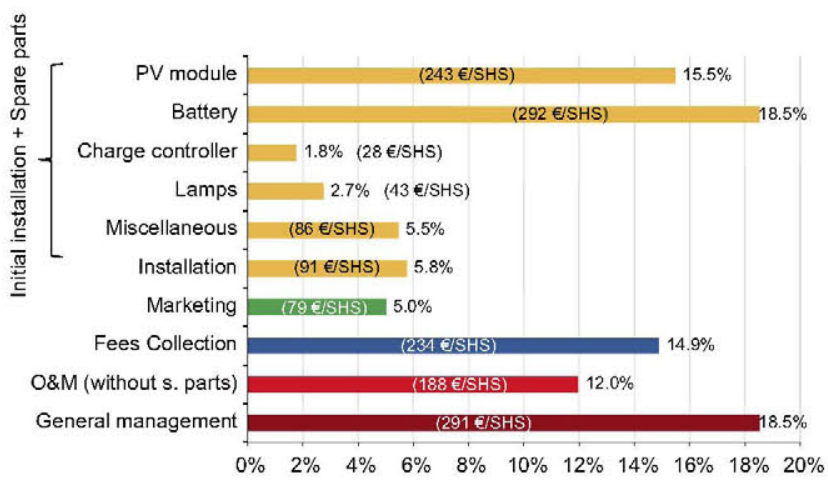

Fig. 6. Detail of the general costs during the whole duration of the programme. The equipment costs are composed both of the initial installation and the spare parts of the maintenance. Figures in brackets indicate the cost per SHS. 
having an initial subscription fee of $227 €$ and a monthly fixed fee of $0.75 €[26]$.

\section{Sensitivity analysis}

Fig. 7 shows that both, the variation of the battery and PV module costs, have the most impact on the total programme cost. This analysis has been carried out varying just the components cost, without changing any other parameter. It is remarkable that battery affects lightly more than PV module. An $80 \%$ variation of the battery cost means a $15 \%$ variation of the programme overall cost. In the case of lamps and charge controllers, the costs variation has much less impact. Note that the carburant of the ESCO vehicles has more influence than lamps and charge controllers in the sensitivity analysis of costs.

Fig. 8 represents the cost variation of the programme regarding the variation of the MTTF value in lamps, batteries and charge controllers, without changing their costs. Obviously, the tendency is that increasing the reliability, the programme overall cost decreases. We can appreciate that battery reliability has more influence than lamps or charge controllers in the global programme cost: $30 \%$ of increase in battery MTTF leads to a reduction of the programme cost of $5.5 \%$.

Increasing reliability means to increase the cost of the kit components. Therefore, the impact on the overall cost depends on the devices cost/reliability relationship.

We can appreciate in Fig. 9 the cost/MTTF relationship of each device when the programme overall cost does not change. That means, for example, whether the battery MTTF decreases $60 \%$ regarding the PERG MTTF figure, and its cost varies in $-77.5 \%$, the programme global cost will not change. These cost/MTTF relation-

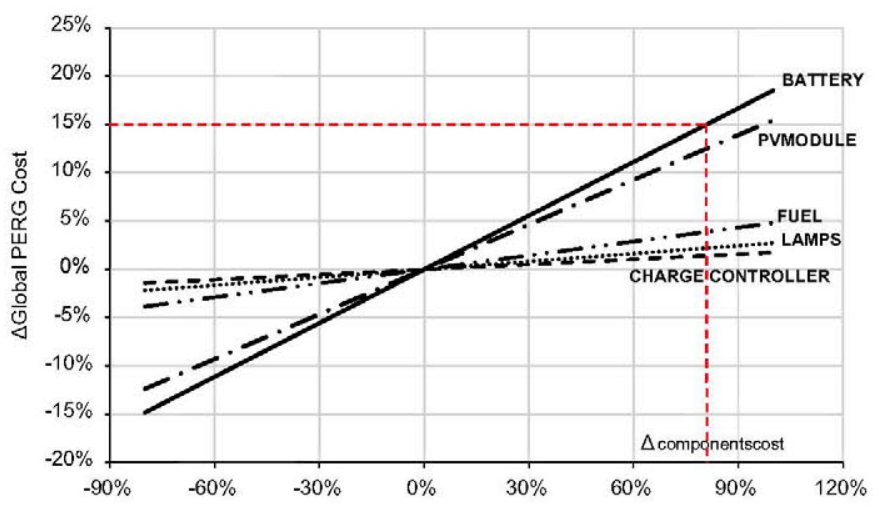

Fig. 7. Sensitivity analysis of the SHS component costs and carburant belonging the PERG programme.

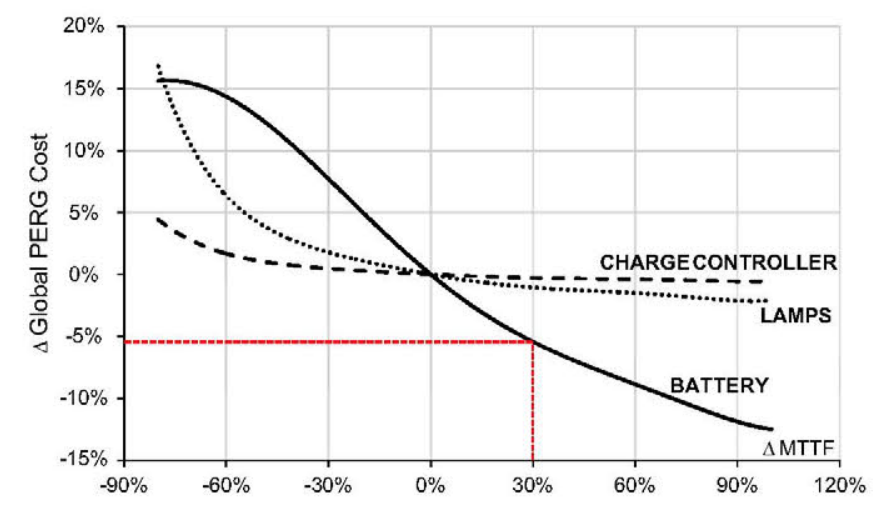

Fig. 8. Sensitivity analysis regarding the reliability variation of the SHS components. ships of SHS components will help us to assess whether a reliability variation can vary positively or negatively the programme overall cost depending on the component costs that were considered.

For example, it is evident that a higher quality battery will be more expensive, but in addition, a higher life cycle, a greater reliability, and a lower maintenance cost. If the battery used at the beginning in the PERG is replaced by a different one having a price $40 \%$ higher than the original, and its MTTF is $80 \%$ longer, the global cost of the programme will be lower than using the original battery, as shown in Fig. 9.

\section{Influence of the SHS spatial density}

The spatial density of SHSs will largely determine the design of the maintenance structure, and will directly affect some unit costs, such as staff, fuel, vehicles, transport of spare parts, the number of local offices and stores, etc.

A management cost analysis of the PERG has been carried out regarding each local agency, taking into account the number of SHSs managed by each agency, in addition to the agency staff and goods, the surface of the local region and its geomorphologic features.

Fig. 10 shows that decreasing the SHS density per $\mathrm{km}^{2}$, the management structure cost increases fitting an exponential function. This is due to the fact that general management costs increase rapidly when the SHS's density is very low. On the one

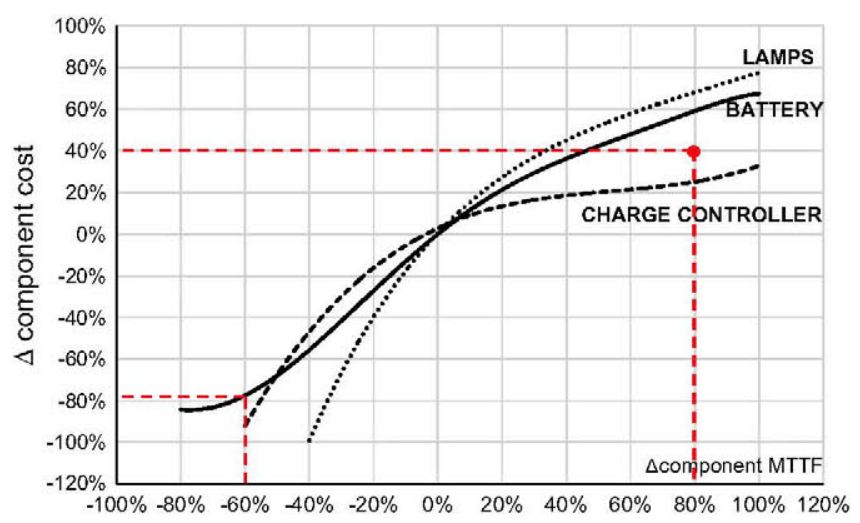

Fig. 9. Relationship between cost and MTTF in order to mantain the overall cost of the programme constant when the MTTF varies.

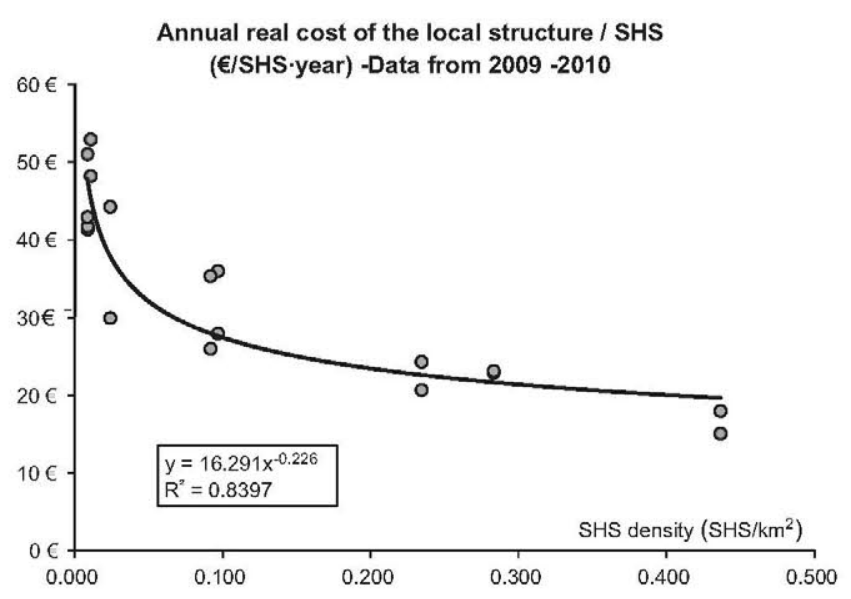

Fig. 10. Management local structure cost per SHS, regarding the SHS density for each region. The geomorphologic features has been considered. 
hand fixed costs are spread among a smaller number of SHSs, and on the other hand, the dispersion and inaccessibility of the systems increases the variable costs.

From this cost/density distribution model, a sensitivity analysis can be carried out to know how the SHS density affects the overall programme cost.

Fig. 11 shows the variation of the global programme costs when the SHS density changes around the PERG density figure. It fits an exponential function. The fact that this variation does not fit a linear function has a great significance in the decentralized rural electrification and it will be a major factor when designing a PVRE programme.

\section{Application example}

An application exercise is here presented to illustrate the influence of the results of this paper in the design of PVRE programmes. We will imagine a hypothetical programme featured by 3 different characteristics regarding the PERG.

(1) The cost of PV modules is reduced in a half.

(2) The number of SHSs does not vary, but the programme's surface will be 10 times smaller than the PERG's area.

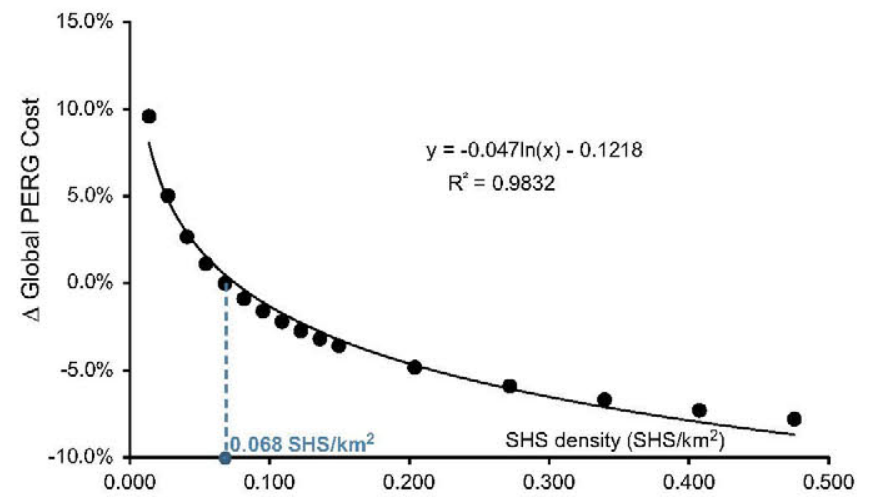

Fig. 11. Sensitivity analysis of the PERG according to the variation of the SHS density.

Table 3

Distinguishing features of PERG and application example programmes.

\begin{tabular}{llll}
\hline Case & Parameter & PERG & Application example \\
\hline 1 & PV module cost $(\epsilon / \mathrm{Wp})$ & 3.35 & 1.675 \\
2 & SHS density $\left(\mathrm{SHS} / \mathrm{km}^{2}\right)$ & 0.068 & 0.68 \\
3 & Battery MTTF (years) & 5.46 & 10.92 \\
& Battery cost $(\epsilon / \mathrm{Wp})$ & 1.31 & 2.29 \\
\hline
\end{tabular}

(3) The battery MTTF will be the double than the current one and its cost will be $75 \%$ higher than indicated in the PERG. It is an open battery that needs distilled water.

Table 3 summarizes the features of the PERG and the example: The overall programme costs resulting of applying the modification of each one of the parameter (cases 1 to 3 ) and all of them together (case 4), are summarized in Table 4:

It can be shown that the case 4 reaches a reduction of $23.1 \%$ of the original overall cost. The increasing of the SHS density (case 2) affects mainly to the $\mathrm{O} \& \mathrm{M}$, reducing in $16.9 \%$ its cost. The reduction of the PV module cost (case 1) affects just the installation activity, and the new battery (case 3 ) increases the installation cost in $11.82 \%$ but reduces the $0 \& \mathrm{M}$ in $27.50 \%$. The management cost does not vary more than $1.0 \%$.

For case 4 , the distribution of costs is shown in Fig. 12. We highlight the following aspects:

- The major cost of the programme is not the battery (18.3\%) or PV module (10\%), but the management (24.3\%). The halving of the PV module cost and the use of a battery with a cost/ reliability relationship as we have chosen, are the reason why the programme cost is reduced. Even though the installation cost increases, the O\&M cost decrease because the number of spare parts, mainly the battery, has been greatly reduced.

- We also see that the management cost changes from $18.5 \%$ to $24.3 \%$. Management is practically a fixed cost, and its reduction depends on increasing the number of SHSs of the programme. Keeping the number of systems in this example and reducing the maintenance costs, the relative cost of management will increase. This fact leads to think that it is necessary to improve the design of maintenance and management structures, that will be the objective of future works, and to implement big rural electrification programmes.

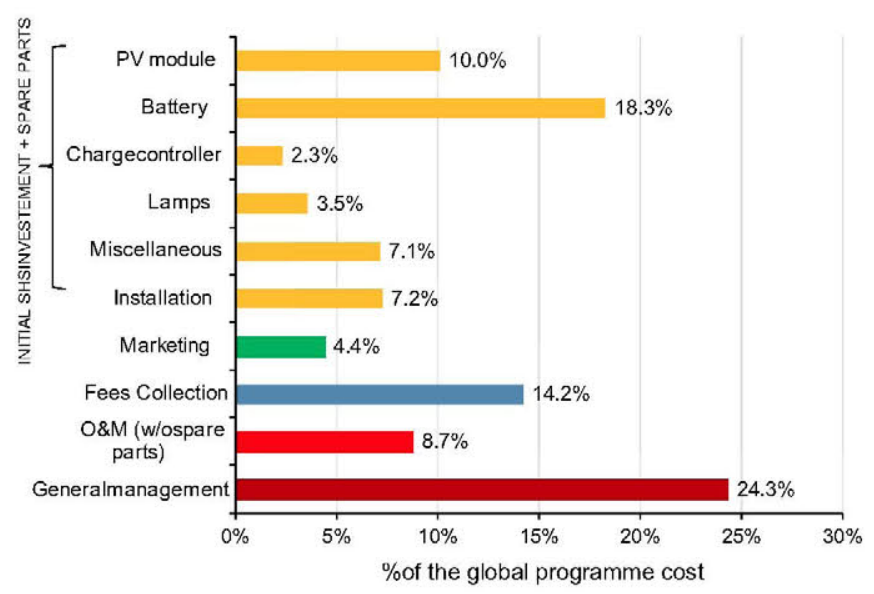

Fig. 12. Details of the overall costs of the application example regarding the SHS component costs.

Table 4

Result figures (in $€ / S H S$ ) after applying the 4 cases features. The percentages indicate the costs variation regarding the original costs.

\begin{tabular}{|c|c|c|c|c|c|c|c|c|}
\hline \multirow[t]{2}{*}{ Case } & \multicolumn{2}{|c|}{ Total cost ( $(\epsilon /$ SHS $)$} & \multicolumn{2}{|c|}{ Installation cost $(\epsilon / \mathrm{SHS})$} & \multicolumn{2}{|c|}{ O\&M cost $(\epsilon / \mathrm{SHS})$} & \multicolumn{2}{|c|}{ Management cost $(\epsilon /$ SHS $)$} \\
\hline & Example & $\triangle$ cost/ PERG (\%) & Example & $\Delta \operatorname{cost} /$ PERG $(\%)$ & Example & $\Delta \operatorname{cost} /$ PERG $(\%)$ & Example & $\Delta$ cost $/$ PERG \\
\hline PERG & 1574 & 0.0 & 631 & 0.0 & 651 & 0.0 & 291 & 0.0 \\
\hline 1 & 1452 & -7.7 & 509 & -19.3 & 651 & 0.0 & 291 & 0.1 \\
\hline 2 & 1434 & -8.9 & 603 & -4.6 & 541 & -16.9 & 290 & -0.3 \\
\hline 3 & 1472 & -6.5 & 706 & 11.8 & 472 & -27.5 & 294 & 0.9 \\
\hline 4 & 1211 & -23.1 & 555 & -12.0 & 361 & -44.5 & 294 & 1.0 \\
\hline
\end{tabular}


The cost of energy in this application example has been reduced from $1.3 € / \mathbf{k W h}$ in the PERG, to $1.0 € / \mathbf{k W h} \mathbf{h}$, and the maintenance cost is reduced from $\mathbf{5 9 . 1} € /$ year.SHS to $45.4 \mathrm{\epsilon} /$ year.SHS. The example has an economic profitability of $\mathbf{1 . 8} \in \mathbf{E M}$ over the programme life.

\section{Conclusions}

The Moroccan photovoltaic PERG programme has been analyzed in order to identify the different costs that intervene in its development. Based on the real data costs of the first 5 years of the programme we have obtained the overall cost for 10 years of maintenance, detailing each activity. The overall programme cost reaches $21 € / \mathbf{W p}$ (or $1574 € / S H S$ ), where $40.1 \%$ of this cost corresponds to the installation phase (631 $€ / S H S$ ); $41.4 \%$ to the O\&M activity (652 $\mathrm{e} / \mathrm{SHS}$ ) and $\mathbf{1 8 . 5} \%$ to the general management (291 $€ / \mathrm{SHS}$ ). The main conclusions achieved in this paper are the following:

- Around $\mathbf{5 0} \%$ of the global cost is invested during the installation phase, and the other $\mathbf{5 0} \%$ in the O\&M period.

- The O\&M of the systems (maintenance, spare parts and fees collection) reaches $\mathbf{7 6} \mathrm{e} / \mathbf{S H S}$. year. This figure is further higher than usually considered in photovoltaic maintenance and it is not covered by user's fees, causing unsustainable financial balances.

- PV module represents just $\mathbf{1 5 . 5 \%}$ in the global cost (243 $\mathrm{E} /$ SHS), versus $18.5 \%$ of the battery ( $292 € / S H S$ ), so battery has to be considered as the most expensive component in decentralized PV rural electrification.

- The maintenance of the open lead batteries leads to add distilled water frequently, whose global cost means $6 \%$ of the overall programme cost ( $9.5 € / \mathrm{SHS}$. year).

- The SHS dispersion and inaccessibility plays an important role in the cost structure, given by a mean SHS density of $0.068 \mathrm{SHS} / \mathbf{k m}^{2}$. This feature affects the maintenance cost. For example, the cost of fuel in this programme represents $5.5 € / \mathrm{SHS}$ - year and the annual rate of distance per SHS traveled by the O\&M vehicles reaches $57 \mathrm{~km} / \mathrm{SHS}$. year.

- It has been calculated the energy delivered by the SHSs, expressed as available electricity for customers, reaching a cost of $1.3 \mathrm{\epsilon} / \mathbf{k W ~ h}$.

Finally, we have shown an application example that demonstrates how taking into account the results of this analysis, the design of the PVRE programmes can be improved. Therefore, this study opens the door to the creation of a designing tool of costs to formulate future PVRE programmes.

\section{Acknowledgements}

We thank to Isofoton Maroc s.a.r.l. for its collaboration in this paper supplying the costs database to achieve this paper.

This study has been partially financed by the Universidad Politécnica de Madrid.

\section{References}

[1] Lorenzo E. Photovoltaic rural electrification. Progress in Photovoltaics Research and Applications 1997;5:3-27.

[2] Huacruz JM, Agredano J, Gunaratne L. Photovoltaics and development. In: Luque A, Hegedus S, editors. Handbook of photovoltaic, science and engineering. 2nd ed.. Chichester: Wiley; 2011. p. 1078-105.

[3] Lemaire X. Off-grid electrification with solar home systems: the experience of a fee-for-service concession in South Africa. Energy for Sustainable Development 2011;15(3):277-83.

[4] Lemaire $X$. Fee-for-service companies for rural electrification with photovoltaic systems: the case of Zambia. Energy for Sustainable Development 2009;13(1):18-23.

[5] Zomers A. The challenge of rural electrification. Energy for Sustainable Development 2003; VII(1):69-76

[6] IEA-PVPS T9-07, 16 cases studies on the deployment of photovoltaic technologies in developing countries (2003).

[7] Martinot E, Cabraal A, Mathur S. World Bank/GEF solar home system projects: experiences and lessons learned 1993-2000. Renewable and Sustainable Energy Reviews 2001;5(1):39-57.

[8] Energy \& Development Research Centre, A review of international literature of ESCOs and fee-for-service approaches to rural electrification (solar home systems), Cape Town, 2003.

[9] Chaurey A, Kandpal TC. Assessment and evaluation of PV based decentralized rural electrification: an overview. Renewable and Sustainable Energy Reviews 2010;14(8):2266-78.

[10] van der Vleuten F, Stam N, van der Plas R. Putting solar home system programmes into perspective: what lessons are relevant? Energy Policy 2007;35(3):1439-51.

[11] Djamin M, Dasuki AS, Lubis AY. Performance evaluation of solar home systems after more than ten years of operation in Indonesia. World Renewable Energy Congress 2000; VI:2022-5.

[12] Nieuwenhout FDJ, van Dijk AL, Lasschuit PE, van Roekel GM, van Dijk VAP, Hirsch D, et al. Experience with solar home systems in developing countries: a review. Progress in Photovoltaics Research and Applications 2001;9:455-74.

[13] Cabraal, A, Best practices for photovoltaic household electrification programs: lessons from experiences in selected countries, World Bank Technical Paper number 324, Asia Technical Department Series. 1996.

[14] Chowdhury SA, Mourshed M, Kabir SMR, Islam M, Morshed T, Khan MR, et al. Technical appraisal of solar home systems in Bangladesh: a field investigation. Renewable Energy 2011;36(2):772-8.

[15] Schäfer M, Kebir N, Neumann K. Energy for Sustainable Development. Research needs for meeting the challenge of decentralized energy supply in developing countries 2011;15:324-9.

[16] Office National de l'Electricité, Rural Electrification in Morocco, available from 〈http://www.one.org.ma〉, 2012.

[17] Tsikalakis A, Tomtsi T, Hatziargyriou ND, Poullikkas A, Malamatenios C, Giakoumelos $\mathrm{E}$, et al. Review of best practices of solar electricity resources applications in selected Middle East and North Africa (MENA) countries. Renewable and Sustainable Energy Reviews 2011;15(6):2838-49.

[18] Carrasco LM, Narvarte L, Peral A, Vázquez M. Reliability of a 13,000-SHS photovoltaic rural electrification programme. Progress in Photovoltaics Research and Applications 2012. http://dx.doi.org/10.1002/pip.2218.

[19] Universal Technical Standard for Solar Home Systems. Thermie B: SUP-99596, EC-DGXVII 1998.

[20] Notton G, Muselli M, Poggi P. Costing of a stand-alone photovoltaic system. Energy 1998;23(4):289-308.

[21] Qoaider L, Steinbrecht D. Photovoltaic systems: a cost competitive option to supply energy to off-grid agricultural communities in arid regions. Applied Energy 2010;87(2):427-35.

[22] Horn, MJ, Solar photovoltaics for sustainable rural electrification in developing countries; the experiences in Peru, ISES Solar World Congress. Göteborg, 2003.

[23] Nouni MR, Mullick SC, Kandpal TC. Photovoltaic projects for decentralized power supply in India: a financial evaluation. Energy Policy $2006 ; 34: 3727-38$.

[24] Ilskog E, Kjellström B. And then they lived sustainably ever after? -assessment of rural electrification cases by means of indicators Energy Policy 2008;36(7):2674-84.

[25] Heuraux C. In: Afrique, editor. L'électricité au cœur des défis africains-Manuel sur l'électrification en. Paris: Karthala; 2010.

[26] 〈http://www.one.org.ma/〉, 2012. 